\title{
EDITORIAL
}

\section{The State of Resident Research in Family Medicine: Small but Growing}

\author{
Peter J. Carek, MD, MS, Guest Editor \\ Arch G. Mainous III, PbD, Guest Editor \\ Department of Family Medicine, Medical University of South Carolina, Charleston, South Carolina \\ Ann Fam Med 2008;6(suppl 1):s2-s4. DOI: 10.1370/afm.779.
}

$\mathrm{R}$ esearch in primary care is essential because clinical care must be based on research evidence, and the evidence base for the majority of care for the population cannot be generated only through animal studies or laboratory- or hospital-based research. ${ }^{1}$ Despite the size and importance of primary care in delivering health care, the research output has been relatively limited. ${ }^{2-5}$ Research in family medicine in the United States is growing, however. ${ }^{6}$ Considering that the generation and application of new knowledge is integral to the further development of family medicine as a discipline, it is important that the skills necessary to conduct scholarly activity be included in residency training to encourage and develop the next generation of investigators, as well as to achieve the more practical goal of applying these skills in clinical practice.

\section{BACKGROUND}

As stated in the Future of Family Medicine report, "participation in the generation of new knowledge must become integral to the activities of all family physicians and, therefore, should be incorporated into family medicine training. ${ }^{17}$ Consistent with these directives, the Annals of Family Medicine, through funding provided by the American Academy of Family Physicians Foundation, has worked with the guest editors to develop

Conflicts of interest: none reported

\section{CORRESPONDING AUTHOR}

Peter J. Carek, MD, MS

Department of Family Medicine

Medical University of South Carolina

9298 Medical Plaza Dr

Charleston, SC 29406

carekpj@musc.edu a peer-reviewed supplement devoted to research conducted by family medicine residents.

A call for papers was conducted through the Association of Family Medicine Residency Directors as well as through announcements made in the Annals of Family Medicine and during national meetings of family medicine organizations. By the deadline, 36 manuscripts were submitted. The initial peer review was completed by the guest editors along with volunteer reviewers. Manuscripts coauthored by either of the editors or originating from residents at their affiliated residency were sent directly to the Annals editorial staff for disposition and decisions to avoid conflict of interest. A summary of these reviews and decisions on whether a revision was requested were forwarded to the corresponding author. The final editorial decision-making process for manuscripts was conducted through the Annals editorial office. Of the 36 papers submitted, 10 were offered the opportunity for revision and resubmission. Some of the submitters chose not to resubmit, but 6 did send in revised manuscripts that were subsequently accepted. The resulting articles, published in this supplement, address a variety of clinical, health services, and primary care epidemiologic questions using qualitative and quantitative methods.

\section{WHAT THE MANUSCRIPTS TELL US}

What do the submitted manuscripts-both those selected for publication in this supplement and those not selected-tell us about the state of resident research?

The manuscripts published in this supplement come from studies based on small numbers of patients, reflecting the resources available to family medicine residents to conduct research. During training, scholarly activity by residents is limited by both financial resources and the time available to conduct such 
projects. The studies therefore follow the appropriate strategy of conducting a project that is feasible to complete during a residency. Although they were small and had limited aims, the projects may eventually lead to larger studies that would enhance the academic basis of family medicine. Many of the submitted manuscripts, including several of those accepted, describe quality improvement projects that appear to have improved awareness, learning, and care in the residency training practices. Linking practice-based research and quality improvement efforts is a potentially useful strategy for generating knowledge that is immediately translatable into practice. ${ }^{8}$

One goal of resident research is the learning that goes with conducting the project. Resident research projects should help to develop reflective, inquisitive clinicians who seek existing knowledge to answer questions and who consider ways to participate in the generation of new knowledge to fill important holes in our knowledge base. Projects should therefore engender learning about the information that we already possess and the information that we need. If the question of a particular project fills an important hole in the literature, and the study uses robust methods that are feasible within the time and resource constraints of residency, the completed project may result in publication. Publication, in turn, is important for disseminating the knowledge gained and promoting its incorporation into clinical practice.

\section{IMPROVING THE RESIDENT RESEARCH PROCESS}

Our review of the 36 submitted manuscripts gave many causes for optimism about family medicine research. Key among them is that residents are clearly participating in scholarly activities during training. Nonetheless, we also noted certain gaps in the research process. On the basis of our review, we identified 2 areas of the research process requiring substantial attention and improvement in residency training. First, faculty members can guide residents in refining research questions to fill important holes in our knowledge. To develop high-quality studies that answer specific research questions, residents and faculty need to be open to observations from practice and need to conduct a thorough review of the medical literature to determine what is currently known and unknown about the clinical question raised. Second, the Discussion sections of manuscripts need to be refined to critically interpret the results of the project regarding their impact on practice, policy, education, or research, furthermore, fully presenting the limitations of a study places the research findings into the appropriate context. Understanding the medical literature and developing critical thinking skills are important in research and other scholarly activities, as they are in the process of patient care

\section{A BROADER LOOK AT THE STATE OF RESIDENT RESEARCH}

Beyond the manuscripts submitted for this supplement, what does the medical literature tells us about the state of resident research? In general, recent evaluations of research in family medicine residencies, which have primarily focused on residency faculty, found minimal productivity in most programs ${ }^{2,9}$; however, many residencies have adopted a scholarly or research requirement for residents. Nearly one-half of residency programs require a resident research project, as this activity is believed to develop critical thinking and patient care skills, as well as to increase the resident's understanding of the medical literature. ${ }^{10}$ Although the faculty may not be producing a great deal of scholarly works, they are encouraging residents to participate in scholarly activity as a learning experience, which is consistent with the overarching goals of the Future of Family Medicine Project. ${ }^{7}$ We were therefore very pleased to receive 36 manuscripts to be evaluated for potential inclusion in this supplement. Although this number represents a small proportion of the resident projects that could have been prepared in manuscript form and submitted, these submissions are a positive sign of research activity by residents, particularly when considered in the context that faculty in only about one-half of family medicine residencies produced any publications over a 3-year period. ${ }^{2}$

At present, residency programs have numerous competing demands when fulfilling educational requirements through patient care activities and rotational experiences. Although its inclusion is often difficult because of these competing demands, a formal program of scholarly activity meets a basic requirement of the Accreditation Council for Graduate Medical Education (ACGME) and develops skills in residents necessary for successful practice. According to the Program Requirements for Residency Education in Family Practice, scholarly activity is an important and required component of family medicine education, and a substantial proportion of residency programs require a resident research project. ${ }^{10,11}$ A defined curriculum in scholarly activity is an avenue that can be used to further develop these skills in residents.

\section{RECOMMENDATIONS}

We hope that this supplement will encourage the scholarly activities of family medicine residents and residency 
faculty, but it is only a small step toward increasing family medicine research capacity and quality. To further scholarly activity in family medicine residency programs, we encourage residency program directors, faculty, and residents to consider the following recommendations:

1. To increase capacity, every family medicine residency program should implement a structured scholarly activity curriculum with the requirement of a completed research or quality improvement project that leads to a presentation or publication. As noted previously, many programs already have research and other forms of scholarly activity. To ensure that these activities result in specific accomplishments, residency programs will to need augment their curriculum. Specifically, programs should seek assistance from family medicine educators and researchers with a history of completed research and quality improvement projects that have been presented or published to serve as mentors and role models. This additional level of expertise should enhance the scholarly activity of the program and assist in the dissemination of the projects' results.

2 . To successfully integrate scholarly activity, residency programs require energetic faculty who possess skills, expertise, experience, and success in this area. Faculty involvement has been noted to be a characteristic of programs that are successful in research. ${ }^{12}$ Currently, only $12.9 \%$ of family practice residency programs require faculty to engage in research or scholarly activity..$^{10}$ Many faculty members may therefore require additional training or incentive to engage in these activities. Alternatively and as previously suggested, family medicine residency programs and departments with a track record of academic success may be able to provide faculty leadership through real-time video conferencing or formal consultative services.

3. To gain experience with the full spectrum of the scholarly activity process and to ensure completion of projects, program directors and faculty should require residents to present their completed works to their peers within their own programs. Also, residents should be encouraged to submit their scholarly work for presentation to larger groups of family medicine physicians, at meetings of such organizations as the North American Primary Care Research Group, the Society of Teachers of Family Medicine, and the American Academy of Family Physicians. Presenting in a peer-reviewed setting will allow for feedback to enhance professional development and potentially increase the likelihood of publication in a peer-reviewed journal if desired. The goal is not to lower the bar of quality for resident research, but to increase residents' likelihood of conducting and capacity to conduct research that is good by the standards of any researcher, resident, or faculty member.

\section{CONCLUSIONS}

Although many residents and residency programs are participating in scholarly activity, we have numerous opportunities to increase research capacity and maintain or enhance research quality. By expanding participation in scholarly activity to all family medicine residents and residency programs, residents' education will be enhanced as they develop critical thinking and patient care skills_-skills that are necessary for individual family physicians to practice high-quality, evidenced-based medicine with their patients. In summary, research and scholarly activity in family medicine residency programs exists, and its further development should be promoted through an emphasis on providing additional support through time allotment and, most importantly, faculty development.

To read or post commentaries in response to this article, see it online at http://www.annfammed.org/cgi/content/full/6/suppl_1/s2.

Key words: Medical education/training; internship and residency/curriculum; faculty; residency programs; research; family practice

Submitted September 24, 2007; accepted September 25, 2007.

\section{References}

1. Mant D, Del Mar C, Glasziou P, Knottnerus A, Wallace $P$, van Weel C. The state of primary-care research. Lancet. 2004;364(9438): 1004-1006.

2. Young RA, De Haven MJ, Passmore C, Baumer JG. Research participation, protected time, and research output by family physicians in family medicine residencies. Fam Med. 2006;38(5):341-348.

3. Mainous AG III, Hueston WJ, Ye X, Bazell C. A comparison of family medicine research in research intense and less intense institutions. Arch Fam Med. 2000;9(10):1100-1104.

4. Askew DA, Glasziou PP, Del Mar CB. Research output of Australian general practice: a comparison with medicine, surgery and public health. Med J Aust. 2001;175(2):77-80.

5. Mendis K, Solangaarachchi I. PubMed perspective of family medicine research: where does it stand? Fam Pract. 2005:22(5):570-575.

6. Pathman DE, Viera AJ, Newton WIP. Research published in 2003 by U.S. family medicine researchers. J Am Board Fam Med. 2007. In press

7. FFM Project Leadership Committee. The Future of Family Medicine: a collaborative project of the family medicine community. Ann Fam Med. 2004;2(Suppl 1):S3-S32.

8. Mold JW, Peterson KA. Primary care practice-based research networks: working at the interface between research and quality improvement. Ann Fam Med. 2005;3(Suppl 1):S12-S20.

9. Young RA, DeHaven MJ, Passmore C, Baumer JG, Smith KV. Research funding and mentoring in family medicine residencies. Fam Med. 2007;39(6):410-418.

10. Neale AV. A national survey of research requirements for family practice residents and faculty. Fam Med. 2002;34(4):262-267.

11. Accreditation Council for Graduate Medical Education. Family Medicine Program Requirements. http://www.acgme.org/acWebsite/ RRC_120/120_prIndex.asp. Accessed September 21, 2007.

12. DeHaven MJ, Wilson GR, O'Connor-Kettlestrings P. Creating a research culture: what we can learn from residencies that are successful in research. Fam Med. 1998;30(7):501-507. 